\title{
Numerical analyses of the connections between representative SFRC prestressed rings of off-shore wind towers
}

\author{
Chandan C Gowda1, Fabio P Figueiredo2, Joaquim A O Barros3 and A. \\ Ventura-Gouveia4
}

(1) Researcher, University of Minho, Guimaraes, Portugal

(2) Researcher, University of Minho, Guimaraes, Portugal

(3) Professor, University of Minho, Guimaraes, Portugal

(4) Professor, Polytechnic Institute of Viseu, Portugal

\begin{abstract}
Off-shore wind towers are the wind farms used to harvest wind energy to generate electricity on water bodies. With the growing need of sustainable production for electricity, off shore wind towers are finding a rapid growth in application. In fact, $4 \%$ of European electricity demands will be generated by offshore wind towers by 2020 in European waters. The current project concentrates on development of an innovative structural system using advanced materials for lightweight and durable offshore towers.

The present paper discusses the nonlinear finite element modelling of the connections between representative prefabricated rings of off-shore wind towers made by steel fibre reinforced concrete (SFRC) and prestressed by a hybrid system formed by carbon fibre reinforced polymers (CFRP) bars and steel strands. The connection between these two rings are assured by post-tension high steel strength cables and concrete-concrete shear friction of treated surfaces. The model takes into account different types of loads and moments originating from rotor, wind and water currents considering the critical loading conditions. The material nonlinear analyses were carried out in FEMIX V4.0 software, considering a 3D constitutive model capable of simulating the relevant nonlinear features of the SFRC, and interface finite elements for modelling the shear friction of the concrete-concrete surfaces in contact. The SFRC rings are modelled by solid elements, and the longitudinal CFRP bars and steel strands by 3D embedded cables.

Parametric studies are carried out in order to assess the influence of different fracture parameters of the SFRC and post-tension level in the cables (steel and CFRP) on the performance of the connection between the two rings.
\end{abstract}

Keywords: Off-shore wind tower, material nonlinear analyses, shear frictional and tied connections. 


\section{Introduction and State of Art}

The growing need of energy to increase the quality of life is exhausting the natural resources like oil, natural gas etc., at a more rapid rate than ever. This pushes the mankind for having more sustainable energy production for the future. One of this energy production is by offshore wind tower, which uses the wind blowing from land to water bodies to produce electricity. The first wind farm was installed in Denmark in 1991 (Giebel and Hasager 2016). 84\% of all offshore wind installations are located in European waters, with remaining $16 \%$ mainly in china, followed by Vietnam, Japan, South Korea, U.S and Taiwan (GWEC 2017).

Fig. 1 shows the global cumulative offshore wind capacity in 2017, which indicates that the production capacity has increased over $450 \%$ from 2011 to 2017 and is continuously growing. This moves the society towards a more productive, costefficient and renewable energy production, reducing the carbon dioxide emissions. One of the steps in reducing these costs is by developing innovative structural systems, which is the main aim of the research project. The current concrete towers involve prefabricated concrete rings of high dimensions assembled on site by post-tensioned steel cables.

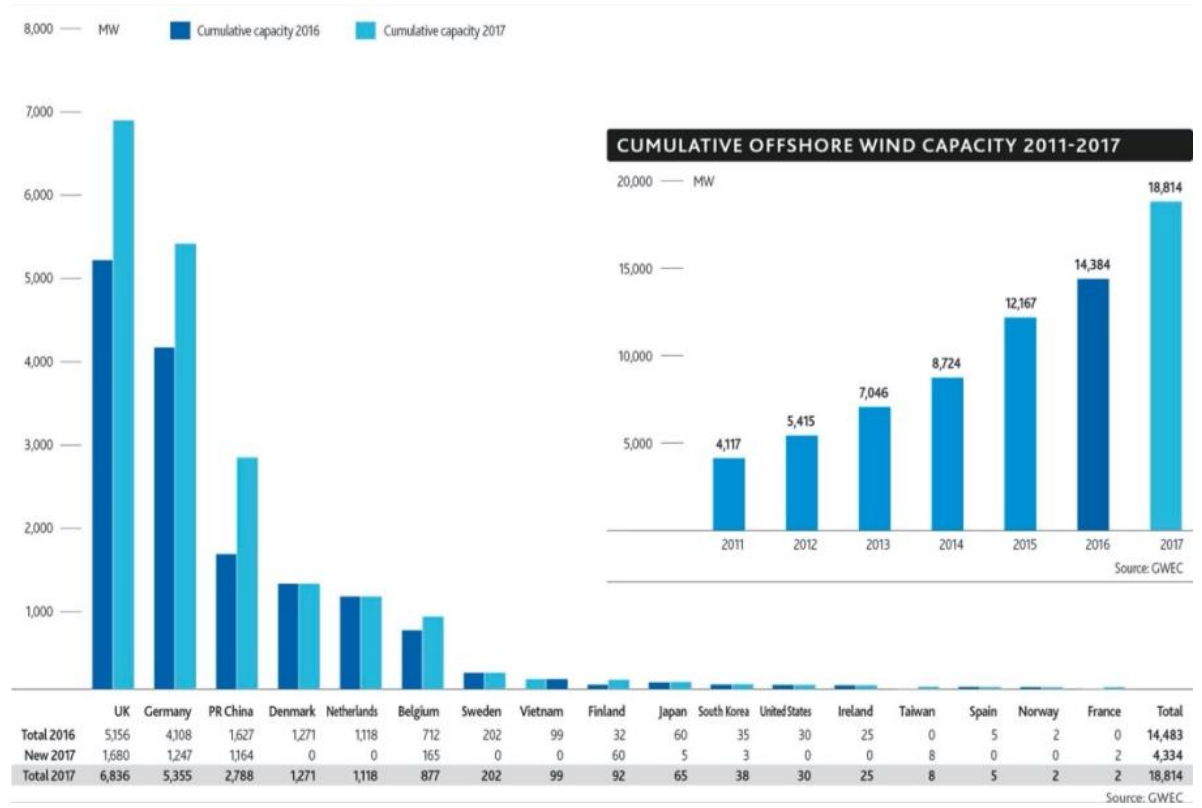

Fig. 1. Global cumulative offshore wind capacity in 2017, (GWEC 2017)

A small change in design or construction process can have significant impact on these type of constructions in terms of cost and schedule savings (Malhotra 2011). The innovative use of composite materials in construction i.e., in support structures and foundations, will reduce fabrication and transportation efforts, resulting in the most cost effective solutions (Malhotra 2007). The main scope of this paper is to perform material nonlinear analysis of the connection between two representative steel fibre reinforced concrete (SFRC) prefabricated rings (of thin wall and variable diameter) of the structural 
system developed in the scope of the research project. The steel fibre reinforcement aims to eliminate the conventional steel bars, allowing to reduce the ring's wall thickness. These rings are prestressed with carbon fibre reinforced polymer (CFRP) bars for taking advantage of the no susceptibility of CFRP to corrosion, while post-tensioned steel cables ensure the connection between consecutive rings, providing simple, fast assembling and disassembling process to the tower's construction. However, high stress gradients are expected to occur in these anchoring zones, a concern that promoted the development of the present material nonlinear analysis.

\section{Model}

\subsection{Geometry and data}

The total height of the tower is 110 meters, with 90 and 20 meters above and below the sea level, respectively. The bottom external radius is 3.6 meters (at $0 \mathrm{~m}$ height, sea bed) and the radius reduces to $1.8 \mathrm{~m}$ (at $110 \mathrm{~m}$ height) at the top. The tower consists of 10 rings, with each ring having a height of 11 meters. The global analysis is discussed in a separate publication (Figueiredo and Barros 2020), and the current paper analyses the connection between two rings by post-tensioned steel cables, subjected to loads and moments generated through different actions of rotor, wind and water (see Fig. 2). According to the global analysis, the bottom most ring, is subjected to worst combination of forces, as a result the connection between the bottom two rings shown in Fig. 2 i.e., the ring resting on the sea bed and the one above is analysed and discussed in the current paper.

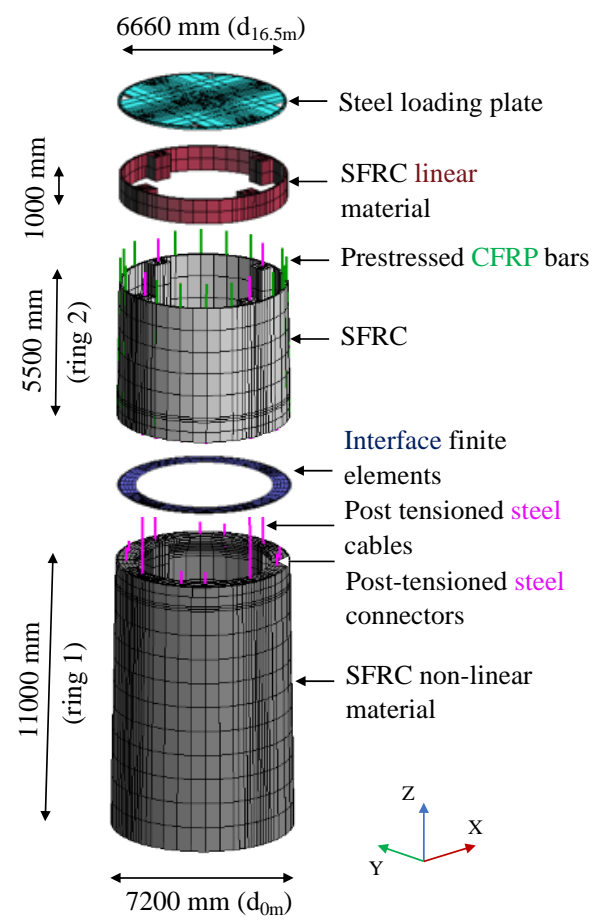

Fig. 2. Model "t_s1" describing different parts. 
In all the analysis carried out in the present paper, the model consists of the bottom full ring $(11 \mathrm{~m})$ and half of the ring above $(5.5 \mathrm{~m})$, with a total height of $16.5 \mathrm{~m}$ (Fig. 2). The radius at the base of the tower is $3.60 \mathrm{~m}$ and the radius at $16.5 \mathrm{~m}$ height is $3.33 \mathrm{~m}$. The tower has a wall thickness of $100 \mathrm{~mm}$. Each ring consists of a horizontal rig of $600 \mathrm{~mm}$ wide at both the extremes, in the top and bottom, connecting the wall at an inclination of 45 degrees, shown in Fig. 3. It also consists of four stiffeners of $600 \mathrm{~mm}$ wide running throughout the length of each ring for $11 \mathrm{~m}$. Post-tensioned steel cables are used to connect the two rings at 12 locations, with four inside the stiffeners and the remaining 8 equally distributed along the perimeter (see Fig. 2). The surface of connection is inclined on both the top and the bottom rings to provide additional shear resistance, shown in Fig. 3. Each ring is prestressed with 16 carbon fibre reinforced polymer (CFRP) bars of $30 \mathrm{~mm}$ diameter placed in the centre of the SFRC wall (Fig. 2).

\subsection{FEM attributes and material properties for the constitutive model}

A 3D multidirectional smeared crack model (Ventura-Gouveia et al. 2008) available in FEMIX 4.0 is used for the numerical simulations. GiD software is used as a pre- and post-processor. The Gauss Legendre $2 \times 2 \times 2$ integration scheme allowing a formation of maximum 3 cracks at each integration point is adopted. Modified Newton-Raphson type 1 iterative algorithm is used, where the stiffness matrix is updated only in the first iteration of each load increment. An independent path behaviour is used with a tolerance of $1 \times 10_{-2}$ in terms of displacement as the convergence criterion.

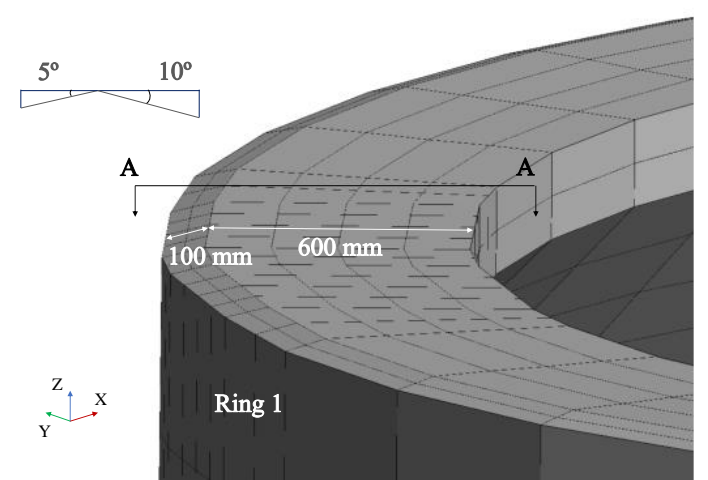

(a)

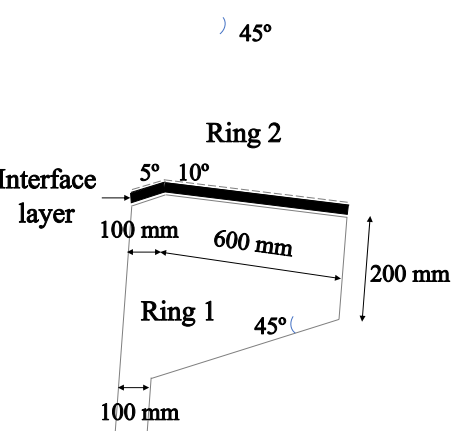

(b)

Fig. 3. Geometry of the circumferential rib connecting two rings (a) 3D and (b) $2 \mathrm{D}$, cross section AA.

8-noded solid hexahedra is used to simulate the SFRC, while 2-noded 3D embedded cable is used to simulate CFRP bars and steel cables. The reinforcements are assumed to be perfectly bonded to concrete elements. Interface finite elements of 8 nodes with Gauss-Lobato integration scheme of $2 \times 2$ are adopted for modelling the connection between consecutive SFRC rings. In order to avoid the development of severe cracking due to the formation of unrealistic stress fields in the zone of the SFRC ring where loads equivalent to the real tower's loading conditions are applied, an additional linear layer of SFRC (1 m thick) is modelled. Furthermore, a stiff steel plate is added, supporting 
the extra linear-elastic SFRC layer to receive the equivalent loads and transfer these loads on the structure to be analysed.

The SFRC developed in a parallel research has a compressive strength of 64 $\mathrm{MPa}\left(\mathrm{fcm}_{\mathrm{cm}}\right)$ and tensile strength of $6.77 \mathrm{MPa}\left(\mathrm{ft}_{\mathrm{t}}\right.$ ), with modulus of elasticity, $42.15 \mathrm{GPa}$ $(\mathrm{E} \mathrm{cm})$ obtained in experimental tests. According to technical data sheet of the products, the adopted steel cables (both connectors and cables) have $40 \mathrm{~mm}$ diameter, yield strength of $1147 \mathrm{MPa}$ and modulus of elasticity of $191 \mathrm{GPa}$, while the CFRP cables have $30 \mathrm{~mm}$ diameter, a tensile strength of $2400 \mathrm{MPa}$ and a modulus of elasticity of $270 \mathrm{GPa}$. By inverse analysis of the results obtained in three point notched beam bending tests, the quadri-linear tensile softening diagram shown in Fig. 4a was obtained for modelling the fracture mode I propagation of the SFRC (presented in Table 2 of section 3.2, Abrishambaf, Barros, and Cunha 2015). The influence of fibre orientation on the postcracking behaviour of SFRC was assessed by performing three point notched beam bending tests with series of specimens of fibre orientation intervals $\left[0-15^{\circ}\right.$ [, $\left[15-45^{\circ}\right.$, $\left[45-75^{\circ}\left[\right.\right.$ and $\left[75-90^{\circ}\right]$. For the present simulations, the fibres were considered to have the best orientation towards the crack planes formed in the tower, which obliges appropriate casting technology for assuring preferential orientation of fibres in the longitudinal axis of a ring. However, the influence of fibre orientation on the response of the tower is assessed in a parametric study described in section 3.2. The crack bandwidth is evaluated as the cube root of the volume of the integration point (IP), being $141 \mathrm{~mm}$ in the current case. The tension and compression behaviour of steel reinforcement (cables and connectors) is simulated by the stress-strain diagram represented in Fig. 4b. More details of the material models can be found in Barros et al. 2013 and in Ventura-Gouveia 2011. The constitutive law of the interface finite elements is described in Valente (2019). In the current analysis, the interface elements are assigned the following properties: slip at the end of the linear bond-slip relationship is $0.5 \mathrm{~mm}$ (so), slip at the peak bond stress is $2.5 \mathrm{~mm}(\mathrm{sm})$, material cohesion of $1 \mathrm{MPa}$, friction angle as $37^{\circ}$, parameter defining pre-peak bond stress-slip relation is $\alpha_{1}=1$, parameter defining post-peak bond stress-slip relation $\alpha_{2}=1$ and a stiffness $\left(\mathrm{K}_{\mathrm{n}}\right)$ of $6.0 \times 10_{7} \mathrm{~N} / \mathrm{mm}$.

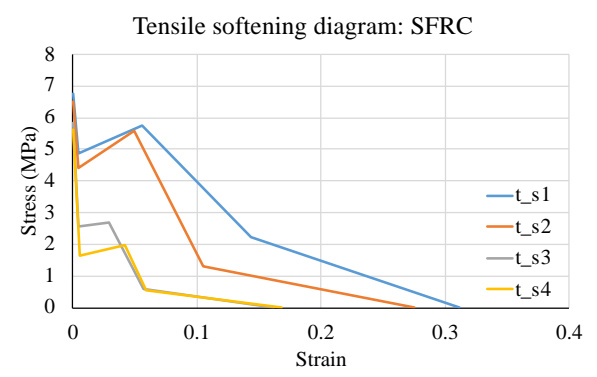

(a)

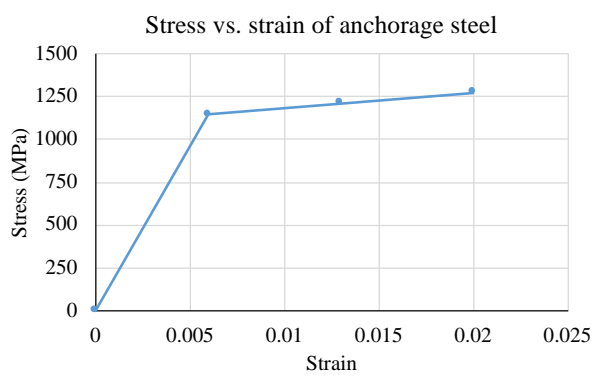

(b)

Fig. 4. Numerical model (a) Tensile softening diagram for different fracture parameters of SFRC (b) Non-linear material property of anchorage steel. 


\section{Results}

\subsection{General results: Model 't_s1'}

As only part of the global model is analysed here, all types of loads acting above the simulated part of the tower, are transformed into the respective forces and moments and applied in the stiff steel plate placed on the top part of the analysed model. The different loads and moments acting on the tower "t_s1" are shown in Table 1, considering the factored loads. More details on the load and moment scenarios arising on the structure are described in Figueiredo and Barros (2020).

Table 1. Different loads considered for the analysis

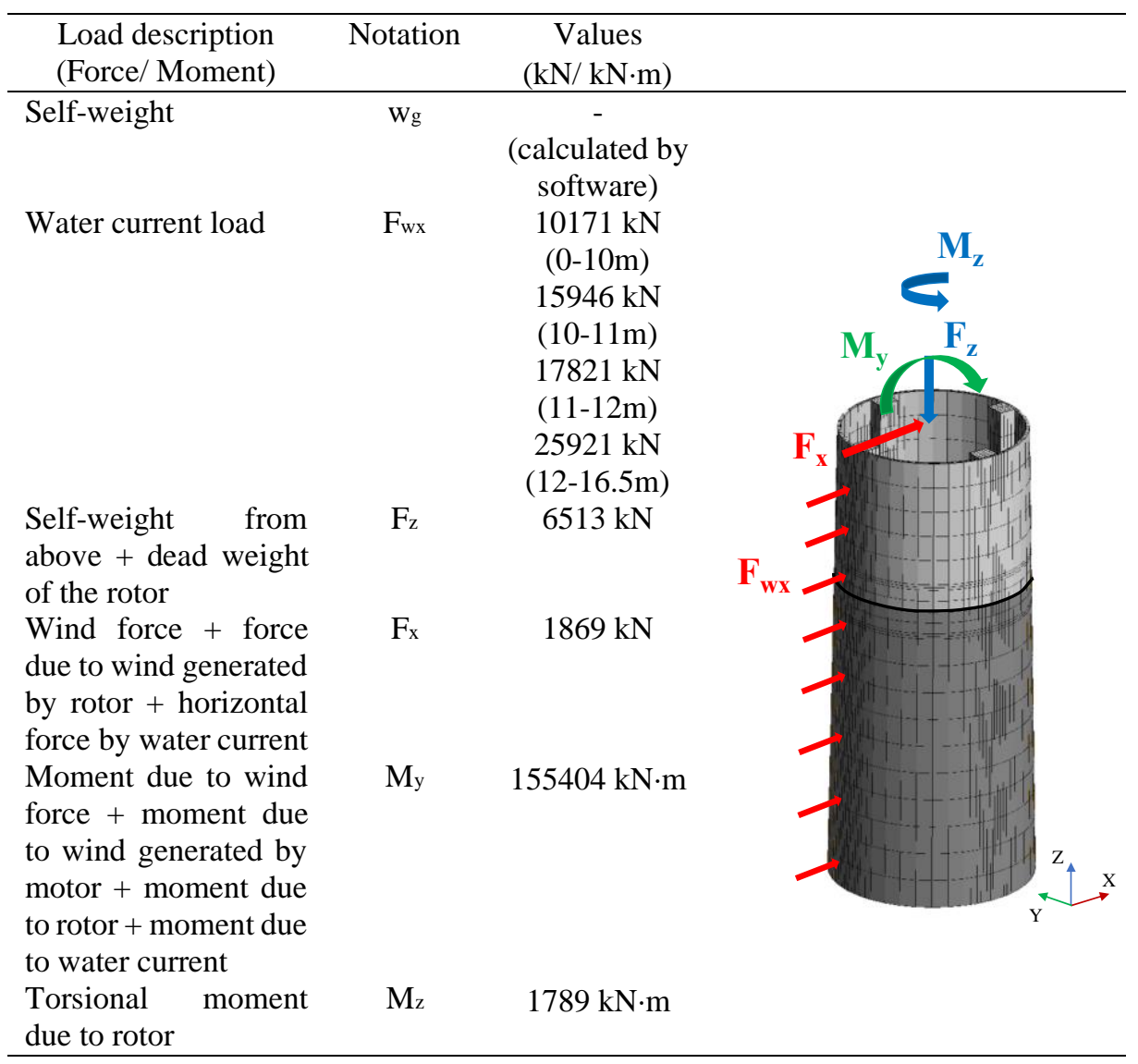

Fig. 5a, shows the graph of force $v s$. displacement of the model, "t_sl" in X-direction. Fig. $5 \mathrm{~b}$ and c, presents the crack pattern at the end of the analysis ( $100 \%$ of $\left.\mathrm{F}_{\mathrm{x}}\right)$, on the bottom and top rings, where the maximum crack width is $0.18 \mathrm{~mm}$ (obtained by multiplying the maximum crack normal strain to the crack bandwidth of the integration point where it is being evaluated). The current software (FEMIX 4.0) presents the crack pattern in five different stages i.e., crack opening, closing, reopening, sliding and fully 
open. Fig. 5b and c, presents only crack opening (red colour) and reopening (cyan colour), as other cracks are not formed.

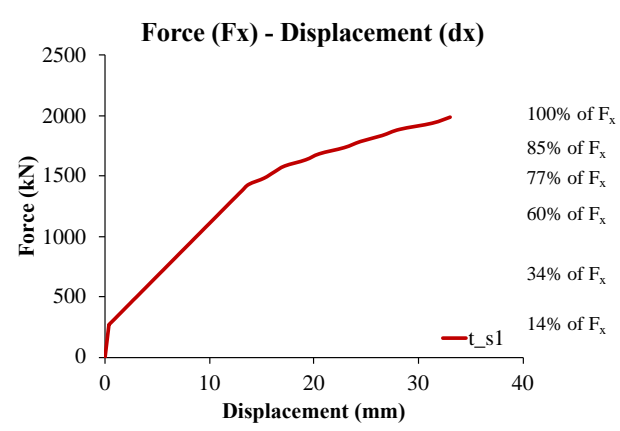

(a)

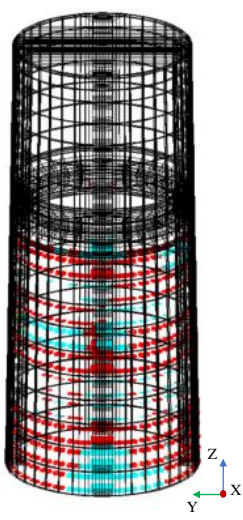

(b)

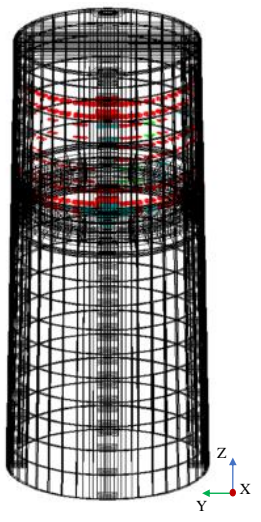

(c)

Fig. 5. (a) Force vs. Deflection; Crack pattern (b) bottom ring \& (c) top ring, model "t_s1".

Fig. 6 shows the evolution of the strains and stresses along the height of the tower in post-tensioned steel cables (Fig. 6a) and in the steel connectors (Fig. 6b), at different integrations points (IP, black dots on the tower) for the indicated load levels (represented in Fig. 6). According to the results, the stresses and strains are well within the yield limits (yield stress is $1147 \mathrm{MPa}$ and the yield strain is 0.006). Stress and strain jumps are obtained at certain IP's at later stages due to crack formation (after $77 \%$ of Fx) and the respective crack at these locations are shown in Fig. 5b and c. At the interface between the two rings, the expected drastic strain/stress jumps are not taking place, specifying that the provided post-tensioned steel connections are sufficient enough to bear the considered factored loads and moments acting on the structure. However, the stress values at the end of the analysis at the connections are higher than the initially provided post-tension (Fig. 6b).

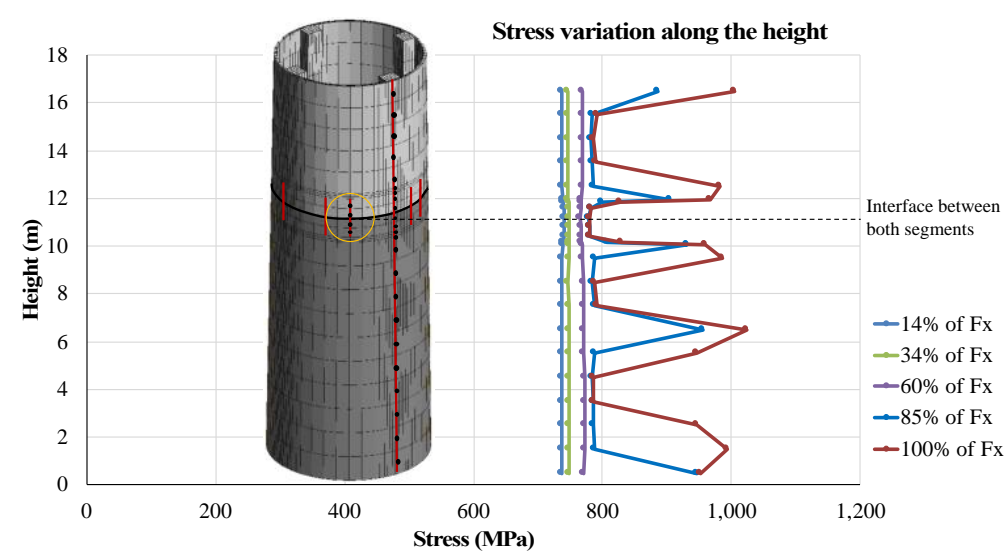

(a) 


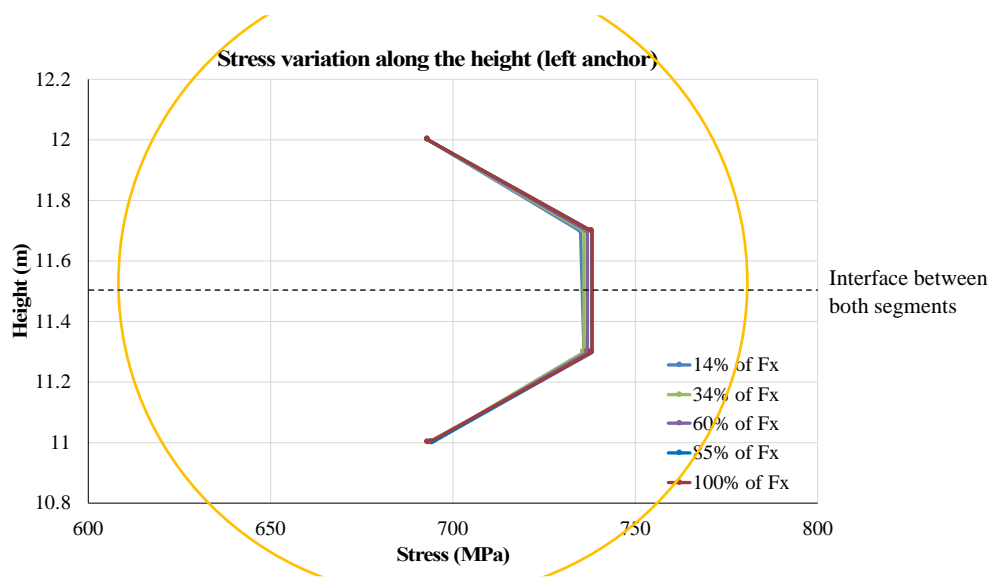

(b)

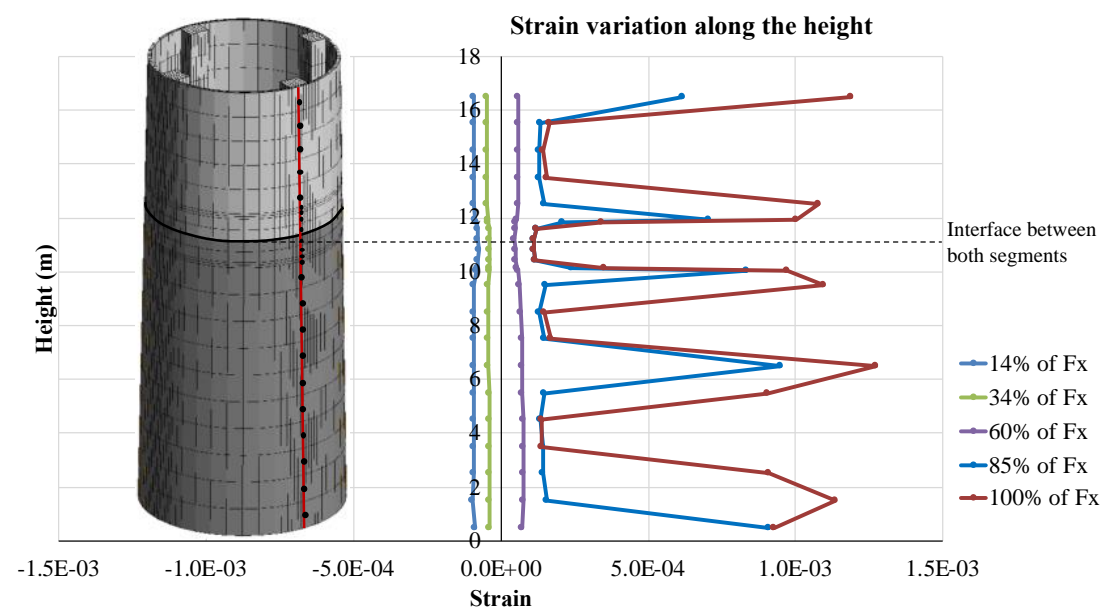

(c)

Fig. 6. Evolution of steel stress: (a) post-tensioned steel cables, (b) post tensioned steel connectors and (c) strain along the height of the tower in post tensioned steel cables for different load combinations, model "t_s1".

Fig. 7 shows the stress distribution in Z-direction (vertical) of the model "t_s1" from two different views. The combination of forces and moments applied in the positive Xdirection, generate tensile stresses (positive values, maximum of $104 \%$ of $\mathrm{ft}_{\mathrm{t}}$ ) on one half of the tower and compressive stresses (negative values, maximum of $58 \%$ of $\mathrm{fcm}_{\mathrm{cm}}$ is reached) on the other half. The maximum shear stress variation on the interface layer between the two rings is lesser than 1.9 $\mathrm{MPa}$. 


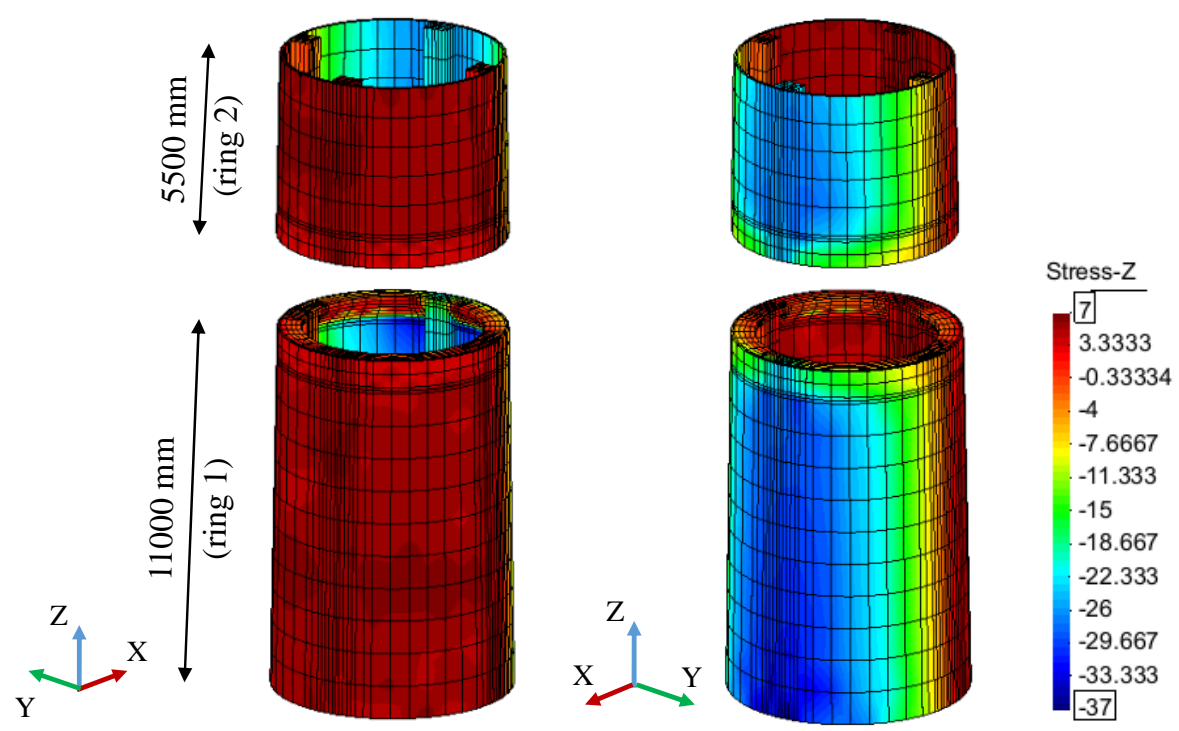

Fig. 7. Stress variation in Z-direction, model "t_s1". Values in MPa.

\subsection{Parametric analysis}

Two parameters are varied to understand the performance of post tensioned steel connections on prefabricated SFRC rings under different loading conditions on the tower. This includes:

(a) variation of fracture parameters of the SFRC based on fibre orientation and

(b) different pre-stress values for the steel and CFRP reinforcement.

Variation of SFRC fracture parameters:

Firstly, the properties of SFRC according to the fibre orientation, based on the experimental research carried out elsewhere (Abrishambaf, Barros, and Cunha 2015). The four different values of softening parameters considered from best to least best, based on the fibre orientation are presented in Table 2 (see also Fig. 4a).

Table 2. SFRC fracture parameters defining stress - strain softening laws

\begin{tabular}{lccccccccc}
\hline Model & $\beta$ & $\alpha_{1}$ & $\alpha_{2}$ & $\alpha_{3}$ & $\xi_{1}$ & $\xi_{2}$ & $\xi_{3}$ & fct & Gf1 \\
& & {$[-]$} & {$[-]$} & {$[-]$} & {$[-]$} & {$[-]$} & {$[-]$} & {$[\mathrm{MPa}]$} & {$[\mathrm{N} / \mathrm{mm}]$} \\
\hline t_s1 & $0^{\circ}-15^{\circ}$ & 0.72 & 0.85 & 0.33 & 0.014 & 0.18 & 0.46 & 6.77 & 6.00 \\
t_s2 & $15^{\circ}-45^{\circ}$ & 0.68 & 0.86 & 0.20 & 0.014 & 0.18 & 0.38 & 6.50 & 5.10 \\
t_s3 & $45^{\circ}-75^{\circ}$ & 0.44 & 0.46 & 0.10 & 0.024 & 0.18 & 0.35 & 5.85 & 2.70 \\
t_s4 & $75^{\circ}-90^{\circ}$ & 0.29 & 0.35 & 0.10 & 0.032 & 0.25 & 0.35 & 5.64 & 2.70 \\
\hline
\end{tabular}

The results of force $v s$. displacement for different fracture parameters of SFRC are shown in Fig. 8a. The performance of SFRC decreases with the increase of fibre orientation angle (less efficient mobilization of the fibre reinforcement mechanisms), leading to higher lateral deflection and the formation of more number of cracks both on 
the upper and the lower rings in the tower. Comparison of crack pattern between model "t_s1" (best SFRC property see Fig. 9a and 10b) and "t_s4" (least best SFRC property, see Fig. 9c and 10d), is shown in Fig. 9.

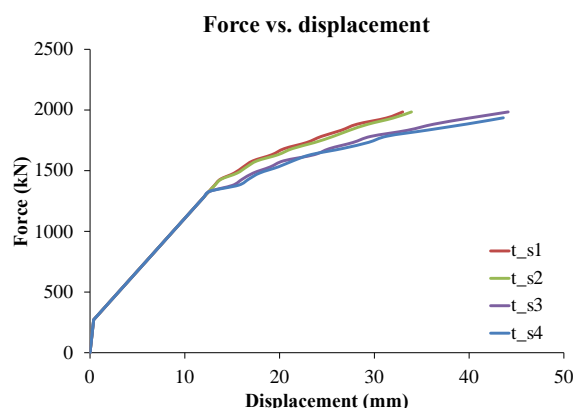

(a)

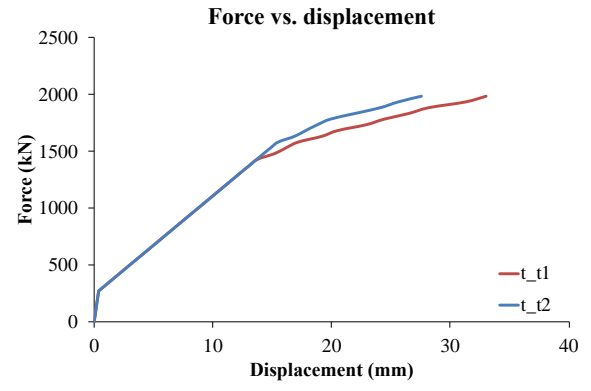

(b)

Fig. 8. Influence of the: (a) post-cracking tensile capacity of SFRC (due to preferential fibre orientation angle) and of the (b) pre-stress level on steel and CFRP reinforcements on the forcedeflection response of the simulated model.

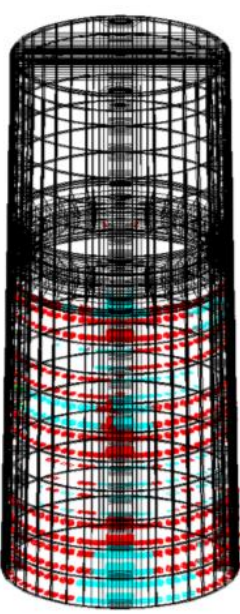

(a)

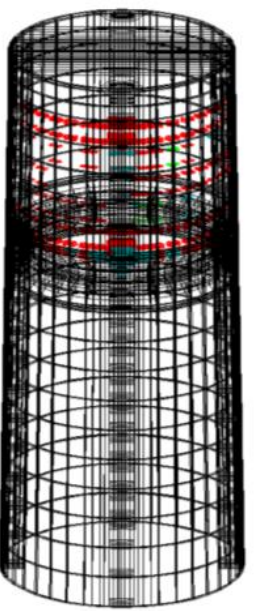

(b)

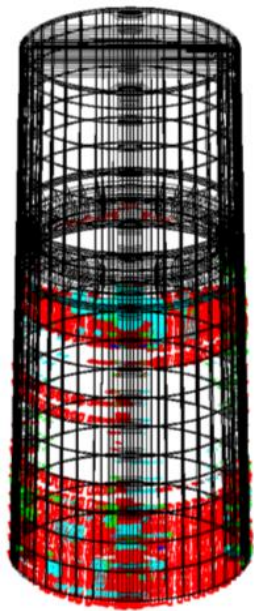

(c)

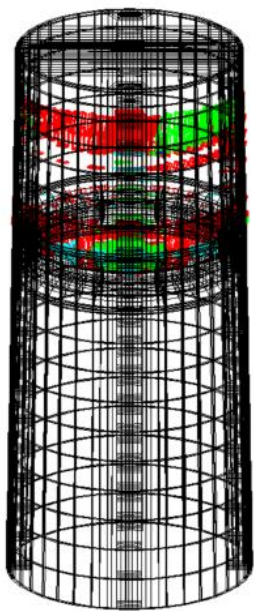

(d)

Fig. 9. Crack pattern: (a) and (b) t_s1; (c) and (d) t_s4.

Variation of pre-stress:

The pre-stress values of steel and CFRP reinforcements are varied according to Table 3. The force $v s$. deflection for both the towers are shown in Fig. 8 b. Tower ' $t$ - 2 ' ' with the increase in $20 \%$ pre-stress on steel and $15 \%$ in CFRP bars, the deflection is reduced by $16.45 \%$ and the maximum crack width is reduced by $6.0 \%$ in comparison with the tower ' $t$ t1'. The respective crack patterns on the top and the bottom segments of both the towers are shown in Fig. 10a-d. Tower ' $t$ - 2 ' ' has lower number of cracks of smaller crack width due to higher pre-stress in the reinforcements. 
Table 3 Pre-stress percentage and values

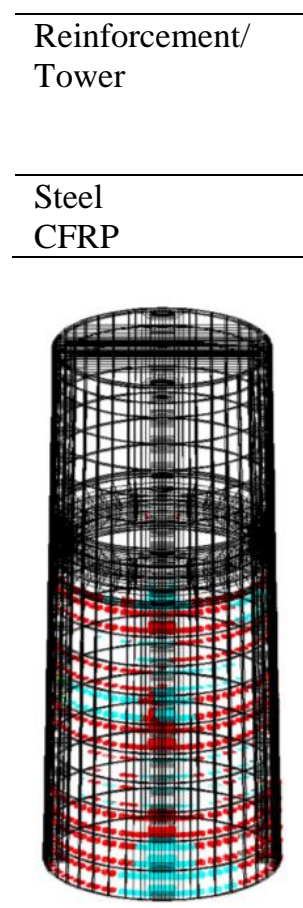

(a)

\begin{tabular}{|c|c|c|c|}
\hline \multicolumn{2}{|c|}{ 't t 1 ' } & \multicolumn{2}{|c|}{ 't t ${ }^{\prime}$} \\
\hline $\begin{array}{l}\text { Pre-stress } \\
\text { percentage } \\
(\%)\end{array}$ & $\begin{array}{l}\text { Pre-stress } \\
\quad(\mathrm{MPa})\end{array}$ & $\begin{array}{c}\text { Pre-stress } \\
\text { percentage } \\
(\%)\end{array}$ & $\begin{array}{c}\text { Pre-stress } \\
\text { (MPa) }\end{array}$ \\
\hline 60 & 756 & 75 & 945 \\
\hline 40 & 960 & 60 & 1440 \\
\hline
\end{tabular}

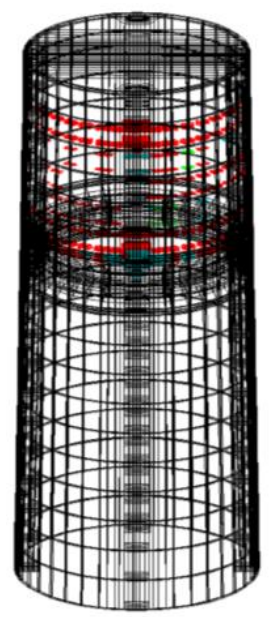

(b)

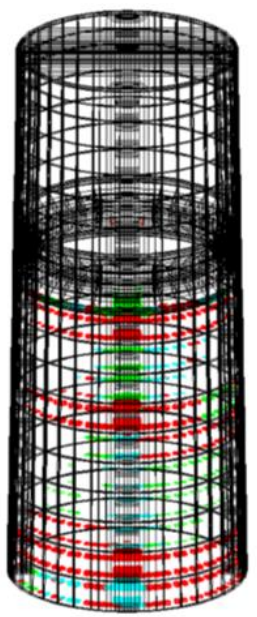

(c)

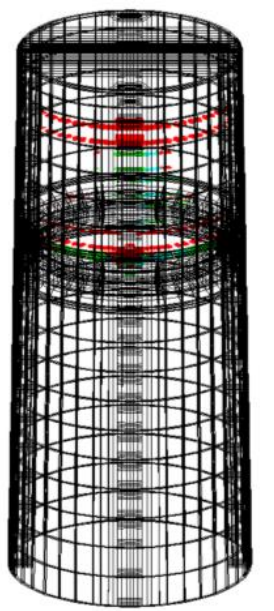

(d)

Fig. 10. Crack pattern: (a) and (b) t_t 1 ; (c) and (d) t_t 2 .

\section{Conclusions}

The following conclusions are obtained based on the results of the FE numerical analysis performed above:

- The proposed material-structural concept of offshore wind tower, combining SFRC, prestressed CFRP bars, post-tensioned steel cables, and post-tensioned steel cables greatly reduces the wall thickness (to $1 / 6_{\text {th }}$ ) with respect to conventional construction;

- The structural behaviour of this tower was assessed by performing material nonlinear analysis and considering some of the most design governing loading conditions, having accomplished the requirements for serviceability and ultimate limit state conditions;

- The maximum crack width obtained in the model with the SFRC of highest post-cracking tensile capacity (due to the consideration of fibre orientation) is $0.18 \mathrm{~mm}$, indicating that no corrosion problems is expected even adopting steel fibres;

- None of the steel reinforcements have yielded nor they are closer to the yielding value, even though some variations are observed at crack locations which are well within yielding limits; 
- By managing the prestress level applied to the CFRP bars and steel strands, the stiffness of the response of the tower can be adapted.

\section{Acknowledgements}

The authors acknowledge the support provided by FEDER funds through the Operational Programme for Competitiveness and Internationalization - COMPETE and by national funds through FCT (Portuguese Foundation for Science and Technology) within the scope of the project InOlicTower, POCI-01-0145-FEDER-016905 (PTDC/ECM-EST/2635/2014).

\section{References}

Abrishambaf, Amin, Joaquim A.O. Barros, and Vitor M.C.F. Cunha. 2015. "Time-Dependent Flexural Behaviour of Cracked Steel Fibre Reinforced Self-Compacting Concrete Panels." Cement and Concrete Research 72. Elsevier Ltd: 21-36. doi:10.1016/j.cemconres.2015.02.010.

Barros, J.A.O., Matteo Breveglieri, A. Ventura-Gouveia, Gláucia M. Dalfré, and Alessandra Aprile. 2013. "Model to Simulate the Behavior of RC Beams Shear Strengthenend with ETS Bars." FraMCoS-8 Fracture Mechanics of Concrete and Concrete Structures, 50516.

Figueiredo, Fabio P, and Joaquim A O Barros. 2020. "Nonlinear Analysis of Offshore Wind Towers in Prefabricated Segments of Prestressed Fibre Reinforced Concrete." In , 2020.

Giebel, Gregor, and Charlotte Bay Hasager. 2016. An Overview of Offshore Wind Farm Design. MARE-WINT: New Materials and Reliability in Offshore Wind Turbine Technology. Denmark. doi:10.1007/978-3-319-39095-6.

Gouveia, António Ventura. 2011. "Constitutive Models for the Material Nonlinear Analysis of Concrete Structures Including Time-Dependent Effects.” University of Minho, Guimaraes, Portugal.

GWEC. 2017. "GWEC Global Wind 2017 Report - A Snapshot of Top Wind Markets in 2017: Offshore Wind." doi:10.1021/jp0213102.

Malhotra, Sanjeev. 2007. "Design and Construction Considerations for Offshore Wind Turbine Foundations." In Proceedings of the International Conference on Offshore Mechanics and Arctic Engineering - OMAE, 5:635-47. doi:10.1115/OMAE2007-29761.

. 2011. Selection, Design and Construction of Offshore Wind Turbine Foundations. Wind Turbines. doi:10.5772/15461.

Valente, T D S. 2019. "Advanced Numerical Models for Analysis of the Behaviour of Structures Strengthened with an Innovative Technique"." University of Minho, Portugal.

Ventura-Gouveia, A., J.A.O. Barros, A. F. M. Azevedo, and J.M. Sena-Cruz. 2008. "Multi-Fixed Smeared 3D Crack Model to Simulate the Behavior of Fiber Reinforced Concrete Structures." CCC2008-Challenges for Civil Construction, 11. 